\title{
Impulsivity, impulsive and reflective processes and the development of alcohol use and misuse in adolescents and young adults
}

\author{
Reinout W. Wiers ${ }^{1 *}$, Susan L. Ames ${ }^{2}$, Wilhelm Hofmann ${ }^{1,3}$, Marvin Krank ${ }^{4}$ and Alan W. Stacy ${ }^{2}$ \\ 1 ADAPT lab, Department of Psychology, University of Amsterdam, Amsterdam, Netherlands \\ 2 School of Community and Global Health, Claremont Graduate University, San Dimas, CA, USA \\ ${ }^{3}$ Department of Psychology, University of Würzburg, Würzburg, Germany \\ ${ }^{4}$ Department of Psychology, University of British Columbia, Kelowna, BC, Canada
}

Edited by:

Adriaan Spruyt, Ghent University,

Belgium

\section{Reviewed by:}

W. Miles Cox, Bangor University, UK

*Correspondence:

Reinout W. Wiers, ADAPT lab,

Department of Psychology, University

of Amsterdam, Roetersstraat 15, 1018

WB Amsterdam, Netherlands.

e-mail:r.wiers@uva.n
This paper contrasts dual-process and personality approaches in the prediction of addictive behaviors and related risk behaviors. In dual-process models, behavior is described as the joint outcome of qualitatively different "impulsive" (or associative) and "reflective" processes. There are important individual differences regarding both types of processes, and the relative strength of both in a specific situation is influenced by prior behavior and state variables (e.g., fatigue, alcohol use). From this perspective, a specific behavior (e.g., alcohol misuse) can be predicted by the combined indices of the behavior-related impulsive processes (e.g., associations with alcohol), and reflective processes, including the ability to refrain from a motivationally salient action. Personality approaches have reported that general traits such as impulsivity predict addictive behaviors. Here we contrast these two approaches, with supplementary analyses on four datasets. We hypothesized that trait impulsivity can predict specific risky behaviors, but that its predictive power disappears once specific behavior-related associations, indicators of executive functioning, and their interaction are entered into the equation. In all four studies the observed interaction between specific associations and executive control (EC) was robust: trait impulsivity did not diminish the prediction of alcohol use by the interaction. Trait impulsivity was not always related to alcohol use, and when it was, the predictive power disappeared after entering the interaction between behavior-specific associations and EC in one study, but not in the other. These findings are interpreted in relation to the validity of the measurements used, which leads to a more refined hypothesis.

Keywords: impulsivity, dual process models, addiction, alcohol, executive control, developmental psychopathology, personality

\section{INTRODUCTION}

In research on individual differences, "impulsivity" is viewed as a multifaceted construct, with aspects related to the inability to stop initiated actions, intolerance to delay, reward sensitivity, and lack of consideration of further consequences of actions (Whiteside and Lynam, 2003; Robbins, 2007; Gullo and Dawe, 2008; de Wit, 2009). In the present contribution, we contrast this trait perspective of impulsivity with the perspective of recent dual-process models, which posit that behavior is the joint outcome of two qualitatively different types of processes: "impulsive" (or associative) and "reflective" (or propositional) processes (Smith and DeCoster, 2000; Strack and Deutsch, 2004; Wiers and Stacy, 2010). We will demonstrate how both types of processes can be assessed and how they jointly predict a variety of risk behaviors, including alcohol misuse. The main difference between the trait impulsivity approach and the dual-process perspective, is that from the latter perspective it is necessary to assess specific impulsive tendencies related to the behavioral outcome of interest, as well as the ability and motivation to control those impulsive tendencies. An individual can score high on general trait impulsivity and still not have strong impulses to engage in a specific behavior that is not motivationally relevant for that individual: "not everyone is tempted by the same stimuli” (Hofmann et al., 2008a; Friese and Hofmann, 2009). From a comparison of these two perspectives (trait impulsivity vs. dual-process models), the central question addressed in this paper emerged: would trait impulsivity still explain unique variance in a specific behavior of interest, after controlling for indices of specific impulsive (or associative) and reflective processes related to that behavior? From a dual-process perspective, it is predicted that this would not be the case. We first summarize the two lines of research, and then address this hypothesis through supplemental analyses of four datasets.

\section{DUAL PROCESS MODELS AND THE PREDICTION OF ADDICTIVE BEHAVIORS}

In recent years, many dual-process models have been proposed in psychology (Sloman, 1996; Smith and DeCoster, 2000; Evans, 2003; Kahneman, 2003; Strack and Deutsch, 2004; Gawronski and Bodenhausen, 2006). In all of these models, behavior is proposed to be the joint outcome of impulsive (or associative) processes and reflective (or propositional) processes. The relative influence of both types of processes in a given situation depends on a 
number of boundary conditions, including personal and situational variables (Hofmann et al., 2008a,b; Wiers et al., 2010). From this perspective, a high score on trait impulsivity can be either due to relatively strong associative processes and/or due to relatively weak reflective processes. This conceptualization is similar to recent neurocognitive models, which describe impulsivity as a lack of frontal-cortical control over impulses and limbic drive (Volkow et al., 2004; Bechara, 2005; Robbins, 2007; Gullo and Dawe, 2008; Crews and Boettiger, 2009). It should be noted that the underlying neural architecture involves far more than two systems, including several corticostriatal loops (Everitt and Robbins, 2005; Robbins, 2007; Everitt et al., 2008), modulated by similar state variables as identified in psychological dual-process models (Robbins, 2007). However, for present purposes, these processes can be summarized as a collection of processes that are involved in associative approach responses and a collection of processes that are involved in control over these impulses, modulated by boundary conditions.

Dual process models have also been adapted to predict addictive behaviors (Stacy et al., 2004; Evans and Coventry, 2006; Deutsch and Strack, 2006; Wiers et al., 2007), as well as other forms of psychopathology (Ouimet et al., 2009). Importantly, from this perspective, behavior-specificimpulsive processes can be measured and evaluated within a dual-process framework. Specific risk behaviors, including alcohol and drug abuse and related problems (e.g., aggression after alcohol, binge eating), can then be better understood.

From the present perspective trait "impulsivity" is clearly a multifaceted construct. First, the strength of behavior-related impulsive processes will differ for different target behaviors. For example, facets of impulsivity and the related concept of disinhibition have been related to different behaviors like alcohol and drug use, aggression, risky sex, and obesity (Nigg, 2000; Cyders and Smith, 2008; Verdejo-Garcia et al., 2008; de Wit, 2009), but clearly not every impulsive person will exhibit all of these behaviors. Individuals have different temptations.

Impulsive (associative) processes build up slowly with experience (Smith and DeCoster, 2000; Strack and Deutsch, 2004; Gawronski and Bodenhausen, 2006), and in the case of alcohol and other drug use this process is pharmacologically enhanced, for example, through the process of incentive sensitization (Robinson and Berridge, 2003). Behavior-specific impulsive responses are learned; they arise from the motivational impact of associations with reinforcement (incentive motivation). Hence, impulsive (associative) processes leading to specific behaviors will first of all depend on an individual's learning history and the rate of learning. This rate is likely to be moderated by individual differences related to reward sensitivity and by developmental stage, with increasing evidence for enhanced appetitive processes with the onset of puberty (Quevedo et al., 2009; Silk et al., 2009). How specific impulsive (associative) processes are assessed is outlined below.

In order for associative processes to be successfully controlled, a number of prerequisites have to be fulfilled. First, people need to be motivated to control their behavior. Without motivation to control, there is no reason to recruit resourceful control processes in order to override associative processes. Rather, people are likely to follow impulsive action tendencies that surpass critical thresholds of activation (Fazio, 1990; Wiers et al., 2007). This view is consistent with the far-reaching proposition that automatic processes constitute the "default" in human decision making (Kahneman, 2003). Second, people will differ with respect to the ability to refrain from acting upon impulses. This aspect of impulsivity is closely linked to conceptualizations referring to the role of executive control (EC) functions or lack of frontal-cortical control over impulses and limbic drive (Crews and Boettiger, 2009), as well as observable behaviors such as lack of self-control. Third, there are important boundary conditions that may critically limit people's momentary capacity to override prepotent impulses. Under certain conditions, such as after alcohol consumption, high cognitive load, stress, or resource depletion, people's control capacities may be impaired such that impulses that are normally held in check "break through" and have an increased impact on behavior (Hofmann et al., 2008a). From a neurocognitive perspective this can be described as state-dependent neuromodulation of corticostriatal systems (Robbins, 2007). We now turn to a brief description of the assessment of each of these factors.

\section{ASSESSING SPECIFIC BEHAVIOR-RELATED IMPULSIVE (OR ASSOCIATIVE) PROCESSES}

Specific behavior-related impulsive processes are typically assessed with paradigms derived from basic memory research or with reaction time (RT) paradigms. The crucial aspect of these measures is that they do not require introspection or self-assessment of motivation, but rather assess spontaneous reactions to motivationally relevant stimuli.

Tests of memory associations using word production in addiction have used various types of word association tests. Common tests have used free word association, in which the participant lists the first word that comes to mind in response to a cue word, phrase, or picture. If such tests do not directly inquire about the target concept (e.g., drug associations), the tests can be characterized as indirect, and may have the capability of assessing implicit processes. Indeed, consistent evidence across diverse paradigms from basic research shows that word association tests are capable of detecting implicit conceptual memory, and associations uncovered in these tests predict the spontaneous activation of cognitions across a wide range of experimental procedures. Consistent findings in cognitive neuroscience support a distinct neural basis of implicit conceptual memory, compared with explicit memory (see for reviews, Stacy et al., 2006a; Stacy and Wiers, 2010). This technique has been adapted for use in alcohol, drug, and other risk behavior research, such as prediction of unsafe sex (Stacy et al., 2006b). In these tests, the alcohol or drug-related cues do not explicitly mention alcohol or drugs but were obtained from norms for likely (perceived) positive outcomes of alcohol use (e.g., having fun, feeling good), and situational antecedents. Hence, participants are instructed to react as fast as possible with their first association to a list of words which are either alcohol or drug-related (having fun...) or not (pleasing relatives...). Another association test used ambiguous words which were either alcohol or drug-related (e.g., draft) or not (e.g., count), and again participants react with their first association. With these measures, numerous studies have found that alcohol and drug use and misuse are predicted by the number of alcohol or drug-related spontaneous associations (for review, see Rooke et al., 2008), in some cases after controlling for explicit cognitions and previous behavior in prospective models (Stacy, 1997; Kelly et al., 
2005; Grenard et al., 2009). It is important to underscore that the nature of test instructions in word association is critical. Indirect association instructions, asking respondents to list the first word that comes to mind, leads to dramatically different results than asking participants to recollect (Stacy et al., 2006a). In a recent comprehensive meta-analysis of over 89 effect sizes from studies sampling nearly 20,000 participants, word association tasks demonstrated the best predictive effects among all indirect tests of alcohol or other drug-related associations studied to date (Rooke et al., 2008).

The second class of measure used to assess memory associations relies on various tests of RT, which usually contrast the effects of within-subject manipulations of stimuli. Among these RT-measures, the Implicit Association Test (IAT) is the most commonly used (Greenwald et al., 1998, 2009; Hofmann et al., 2005). Many studies have used alcohol and drug varieties of the IAT (Wiers et al., 2002, 2005; Jajodia and Earleywine, 2003; Palfai and Ostafin, 2003; Houben and Wiers, 2006a,b, 2007a,b, 2008a,b; McCarthy and Thompsen, 2006; Ostafin and Palfai, 2006; Ames et al., 2007; Thush and Wiers, 2007; Thush et al., 2007; Houben et al., 2010). In an IAT two "target" concepts (typically alcoholic vs. soft drinks) are paired with two attribute concepts (typically positive and negative valence), using two response keys. This can be done in one of two ways: alcohol and positive affect on one side, and soft drinks and negative affect on the other side or alcohol and negative on one side and soft drinks and positive on the other side. The idea underlying the IAT is that two concepts that are more closely related in memory should facilitate responses (faster responses and less errors) when they share the same response key, and impair responses when they do not share the same response key. Hence, when people hold stronger alcohol-positive affect associations than soft drink positive affect associations, they should be faster in the first categorization than in the second. Following other research with the IAT, most studies have assessed the relative strength of positive affect and negative affect associations with alcohol (as opposed to the contrast category). However, some studies have also studied positive and negative associations separately and found both (Jajodia and Earleywine, 2003; Houben and Wiers, 2006b; McCarthy and Thompsen, 2006). Other associations have been assessed as well, for example, between substance use and arousal (Wiers et al., 2002, 2005; Houben and Wiers, 2006b), and between substance use and approach vs. avoidance tendencies (Palfai and Ostafin, 2003; Ostafin and Palfai, 2006). The overall picture is that although people have both appetitive associations (positive and arousing outcomes and approach motivation) and negative associations (or avoidance), the relative strength of the appetitive associations is a better predictor of alcohol and substance use. For example, in a 1-year follow-up study, positive affect and arousal associations predicted the level of drinking in adolescents a year later, together with the relative strength of explicit negative expectancies (Thush and Wiers, 2007).

Other RT-measures have been developed as well to assess associative processes in response to alcohol and drug cues, including semantic priming (Weingardt et al., 1996; Zack et al., 1999), other tests of affective associations (De Houwer and De Bruycker, 2007; Payne et al., 2007), and measures of approach vs. avoidance tendencies (Field et al., 2004, 2008a; Wiers et al., 2009b). In addition, measures of attentional bias for alcohol or drug stimuli are often assumed to reflect associative memory processes, although other mechanisms have been proposed as well (Cox et al., 2006; Field and Cox, 2008). Note that we do not argue that the measures summarized here are process-pure measures of impulsive processes. They are not. Mathematical modeling has provided strong evidence that RT-measures like the IAT partly assess associative/impulsive processes, but may also be influenced by reflective processes, involved in the switching of response-assignments (for example Conrey et al., 2005; Sherman et al., 2008). The point here is that they are the most-predictive currently available indices of impulsive (associative) processes related to specific risk behaviors.

In summary, a variety of measures have been developed which can be used to assess impulsive (associative) processes related to specific risk behaviors. In many studies these measures have been demonstrated to predict alcohol and drug use, in many cases also after controlling for explicit cognitions (see for reviews, Ames et al., 2006; Rooke et al., 2008; Stacy and Wiers, 2010; Wiers et al., 2010).

\section{ASSESSING REFLECTIVE PROCESSES: ABILITY TO CONTROL}

Reflective processes are composed of the following two different components. First, there must be a self-regulatory goal (typically related to long-term goals), and second, there must be the ability to resist temptations that interfere with the long-term goals. In order to resist impulsive influences on behavior in the service of long-term goals, individuals need to draw on a variety of executive cognitive functions (Giancola, 2000; Hofmann et al., in press). Here, we treat EC functions as a broad label that subsumes a collection of more specific sub-functions, supported by the frontal brain regions, which enable the higher-order control of behavior (Smith and Jonides, 1999; Miyake et al., 2000; Robbins, 2007). Most centrally, EC functioning involves capacities such as (1) allocation of attention to goal-relevant information, (2) flexible, context-relevant updating of goal-relevant information in working memory, and (3) inhibition of prepotent irrelevant responses that interfere with the present goal at hand (Smith and Jonides, 1999). Through the orchestrated use of these executive functions individuals may succeed in regulating behavior in accordance with their long-term goals (i.e., to refrain from alcohol consumption) even in the face of competing association-driven action tendencies. One prediction that can be derived from this framework is that individuals high in executive functions should show less impulsively driven behavior because they successfully inhibit or counteract the impact of associative processing on behavior. Note that in the context of risky behaviors, this is usually thought of as the moderation of impulsive action tendencies to engage in risky behaviors. However, it is also possible that reflective processes may sometimes lead to risk behaviors: intelligent sensation seekers may reflect upon and weigh the pros and cons of risky behaviors (e.g., jump a cliff, binge-drink) and rationally decide to take the risk, which is likely to involve control over automatic fear reactions (this could be described as "rational risk behavior").

\section{ASSESSING REFLECTIVE PROCESSES: MOTIVATION TO CONTROL}

Importantly, EC does not only involve general abilities to regulate impulsive tendencies; it also involves motivation to control and effects from fluctuating states such as fatigue, stress, and acute effects of alcohol and other drugs. People can have a variety of reasons 
to limit their drinking, including religion, health consequences or other risks. A number of related concepts have been proposed to assess motivation to limit drinking, including reasons to abstain, negative expectancies and motivation to change, with the latter construct applying only to people who experience problems with alcohol use (Chassin and Barrera, 1993; Jones and McMahon, 1998; Maggs and Schulenberg, 1998; Stritzke and Butt, 2001; McEvoy et al., 2004). Note that in the empirical studies reviewed here, including the studies described in more detail later in this paper, the focus is on individual differences in the ability to control impulses, not on individual differences in motivation to control. We are aware of only one study which experimentally tested whether a change in motivation to control would have a moderating effect on the relationship between impulsive processes and alcohol use (Thush et al., 2009). The main hypothesis in that study was that motivation to change drinking would increase as a consequence of a motivational interview (experimental group only), and that this change would lead indirectly to reduced levels of drinking, through increased moderation of associative processes. Unfortunately, no effect was found motivation to change, therefore the moderation hypothesis could not be tested.

\section{STATE-DEPENDENT DIFFERENCES IN THE PREDICTION OF RISK BEHAVIORS}

In addition to motivation to control, there are a number of temporary conditions which can promote impulsive behavior, including stress (Sher et al., 2007), fatigue or "ego-depletion" (Baumeister, 2003), "hot" visceral states or craving (Nordgren et al., 2008; Sayette et al., 2008), or hunger in case of eating (Nederkoorn et al., 2009b), and acute alcohol or drug use (Field et al., 2008b; Schoenmakers et al., 2008). From the present perspective, all of these factors can be viewed as temporarily favoring impulsive over reflective processes. For instance, it has been found that the impact of associative processing on behavior tends to increase under cognitive load (Friese et al., 2008), alcohol (Hofmann and Friese, 2008), and ego depletion (Hofmann et al., 2007, for a review, see Hofmann et al., 2008a).

\section{SPECIFIC ASSOCIATIONS AND EXECUTIVE CONTROL JOINTLY PREDICT RISK BEHAVIORS}

In support of the combined influence of specific associative (impulsive) processes and EC, a number of recent studies demonstrated that executive functions moderate the relationship between associative processing and behavior (Grenard et al., 2008; Hofmann et al., 2008b; Thush et al., 2008; Wiers et al., 2009a; Friese et al., 2010; see for a conceptually similar study Finn and Hall, 2004). The general pattern of results of these studies is represented in Figure 1. It was found that associative processes predicted risky behavior in low but not in high WM individuals (in one study there was still some prediction for high WM individuals, Grenard et al., 2008), while explicit attitudes or expected pros and cons predicted in high but not in low WM participants. Studies that were re-analyzed for the present paper are those that included a measure of trait impulsivity, in addition to the indices of associative impulsive processes and EC or self-control (Grenard et al., 2008; Thush et al., 2008; Friese and Hofmann, 2009). The other studies are first briefly summarized, followed by a somewhat more elaborate description of the studies that were re-analyzed.
One set of studies used measures of working memory capacity (WMC) as proxies for EC functioning. WMC measures primarily tap the capacity to direct selective attention to goal-relevant information and to shield this information from interference (Kane et al., 2001). For instance, two studies showed that automatic associations toward candy predicted actual eating behavior more strongly among individuals low rather than high in WMC (Hofmann et al., 2008b, 2009a). Conversely, high WMC individuals acted more strongly in accordance with their goal to forego sweets, suggesting that WMC supports successful self-regulation over food consumption (Hofmann et al., 2008b). Analogous moderator effects of WMC on the expression of impulsive action tendencies have been found with regard to alcohol use and problems in adolescents, including two studies re-analyzed and discussed below (Grenard et al., 2008; Thush et al., 2008). In a recent study it was also shown that effects of positive alcohol associations on attentional bias for alcohol (assessed with eye movements) were moderated by WMC (Friese et al., 2010). In social drinkers with low WMC, positive alcohol associations (assessed with an IAT) predicted that attention was drawn to and captured by alcohol pictures, but this was not the case for social drinkers with high WMC.

A second set of studies used measures of prepotent response inhibition to more directly tap into the capacity to inhibit impulsive action tendencies. For instance, a recent study assessed prepotent response inhibition with a classical Stroop task and found that individuals with strong response inhibition showed no relationship between automatic alcohol associations (assessed with an IAT) and drinking behavior whereas this relationship was strong among those individuals with poor response inhibition (Houben and Wiers, 2009). Another recent study also used a classical Stroop as moderator variable (Wiers et al., 2009). This study also demonstrated the relevance of assessing specific associations related to the behavior of interest, in this case aggression after drinking alcohol in men. Based on an evolutionary theory, it was hypothesized that associations between alcohol and power would be predictive of aggression after drinking, especially in men with relatively poor response inhibition. Two IATs were assessed, one assessing alcohol-power associations and a control IAT, assessing alcohol-arousal associations. As hypothesized, aggression after alcohol use was predicted by the strength of alcohol-power associations in men with poor response inhibition, but not in men with good response inhibition. Moreover, the alcohol-arousal associations did not show this moderated relationship to aggression after drinking, emphasizing the importance of assessing specific associations related to the behavior of interest.

Given the above findings, one is led to ask to what degree WMC and response inhibition effects overlap. A recent study addressed this question by assessing both WMC and prepotent response inhibition with a Stop-signal task (Hofmann et al., 2009). The authors found that both constructs interacted independently with automatic affective reactions in predicting impulsive behavior. This finding suggests that, consistent with a fractionated account of executive functioning (Miyake et al., 2000), WMC and inhibition tasks tap separate executive components that contribute independently to impulse control. Taken together, the findings reported in this section converge well on the idea that executive functions are strongly involved in the successful inhibition of impulsive action tendencies that may be incompatible with one's long-term goals or standards. 


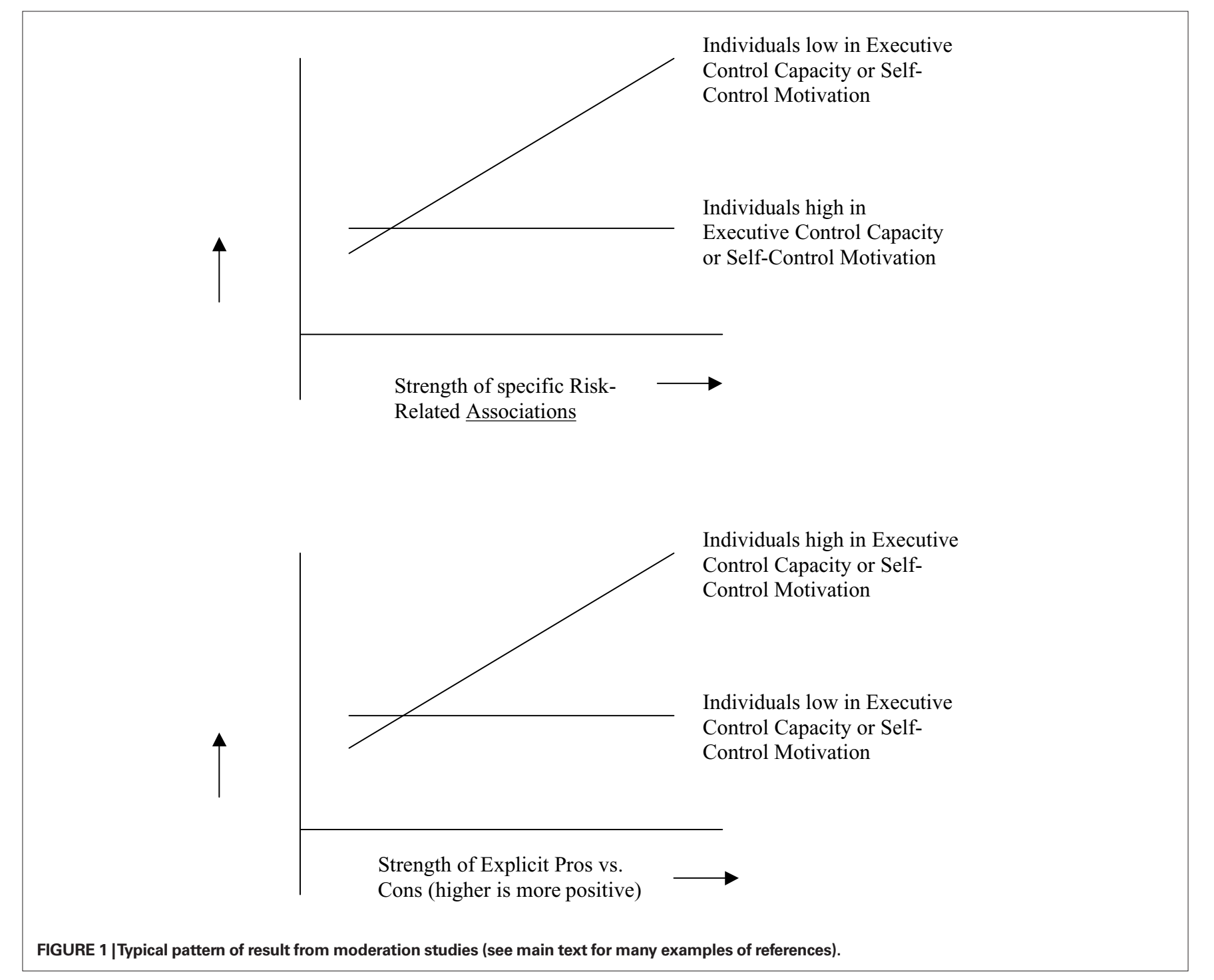

\section{DUAL PROCESS MODELS, TRAIT IMPULSIVITY, AND SENSATION SEEKING}

How do the concepts discussed so far (behavior-specific impulsive processes, EC, and their interaction), relate to more general trait variables like impulsivity and sensation seeking? As noted above, impulsivity and sensation seeking are concepts that are defined in many different ways, which may represent different facets of the concepts. In line with the dual-process discussed above, we think it is good to distinguish between sensation seeking defined as rewardsensitivity on the one hand, and impulsivity, defined as lack of motivation and/or ability to control action tendencies in face of long-term consequences, on the other hand. Similar arguments have been made, based on neurocognitive (Crews and Boettiger, 2009), psychometric (Woicik et al., 2009), and on developmental considerations (Steinberg et al., 2008). Hence, a person scoring high on sensation seeking is expected to generally respond strongly to rewarding, exciting stimuli, and through experience will form strong specific associations. A person scoring high on impulsivity is expected to have problems controlling impulses, once these are triggered.
Note that impulsivity and sensation seeking are often confused, which is understandable from the present perspective; both a strong impulse and a lack of control over the impulse can lead to the same outcome behavior. However, there are also important differences between the two concepts. First, impulsivity is negatively related to intelligence (Shamosh et al., 2008) but sensation seeking is not - if anything it appears to be positively related to intelligence (Raine et al., 2002). Intelligence is also related to WMC and other executive functions (Conway et al., 2003). Second, the developmental pathways of the two traits are markedly different: impulsivity gradually decreases with age, reflecting the gradual maturation of cortical areas involved in cognitive and affective control (Steinberg et al., 2008); sensation seeking, in contrast, peaks in adolescence, probably reflecting the earlier maturation with puberty of mesolimbic circuits involved in appetitive drives (Steinberg et al., 2008; Dahl and Gunnar, 2009). Figure 2 depicts hypothetical relationships among trait impulsivity, sensation seeking, and elements of the behavior-specific dual-process model. 
From these general considerations, we hypothesized that impulsivity should be negatively related to measures of self-regulation or EC and that sensation seeking should be positively correlated with measures of behavior-specific associations. Many studies have found positive correlations between impulsivity and/or sensation seeking and addictive behaviors (Ames et al., 2005; VerdejoGarcia et al., 2008; de Wit, 2009; Woicik et al., 2009). Our central hypothesis here is that once behavior-specific associative processes are assessed as well as a measure of motivation and/or ability to control, these general trait variables should loose their predictive power. As a first step to test this hypothesis, we considered four recent datasets (published in three papers) and re-analyzed them where necessary. We defined three more specific hypotheses:

1. Robustness: We hypothesized that specific associations moderated by EC would remain predictive of specific risky behaviors after controlling for trait impulsivity (as well as for sensation seeking, when assessed).

2. Redundant Predictors: We hypothesized that including the interaction between behavior-specific associations and EC would reduce the predictive validity of trait impulsivity (and sensation seeking) to non-significance, thus rendering these general trait variables redundant predictors. Such a finding would support the idea that our specific impulse predictor in concert with a measure of EC encompasses the potential effects of trait impulsivity on behavior.

3. Alternative moderator: We hypothesized that trait impulsivity could play the same role as our EC moderators and function as a moderator of behavior-specific associations. This was tested by replacing EC as a moderator with trait-impulsivity, as a moderator of the prediction of behavior-specific associations in our interaction models of the predictive effects of behaviorspecific associations.

These hypotheses are addressed in supplementary analyses of four datasets, in which specific impulsive processes and indices of control were assessed, along with a self-report questionnaire assessing impulsivity (and when possible sensation seeking).

\section{SUPPLEMENTARY ANALYSES \\ STUDY 1 (THUSH ET AL., 2008)}

In this study, 88 Dutch adolescents performed a series of computerized tasks and questionnaires in small groups. The Dependent Variable was a composite score of 1-month prospective alcohol use

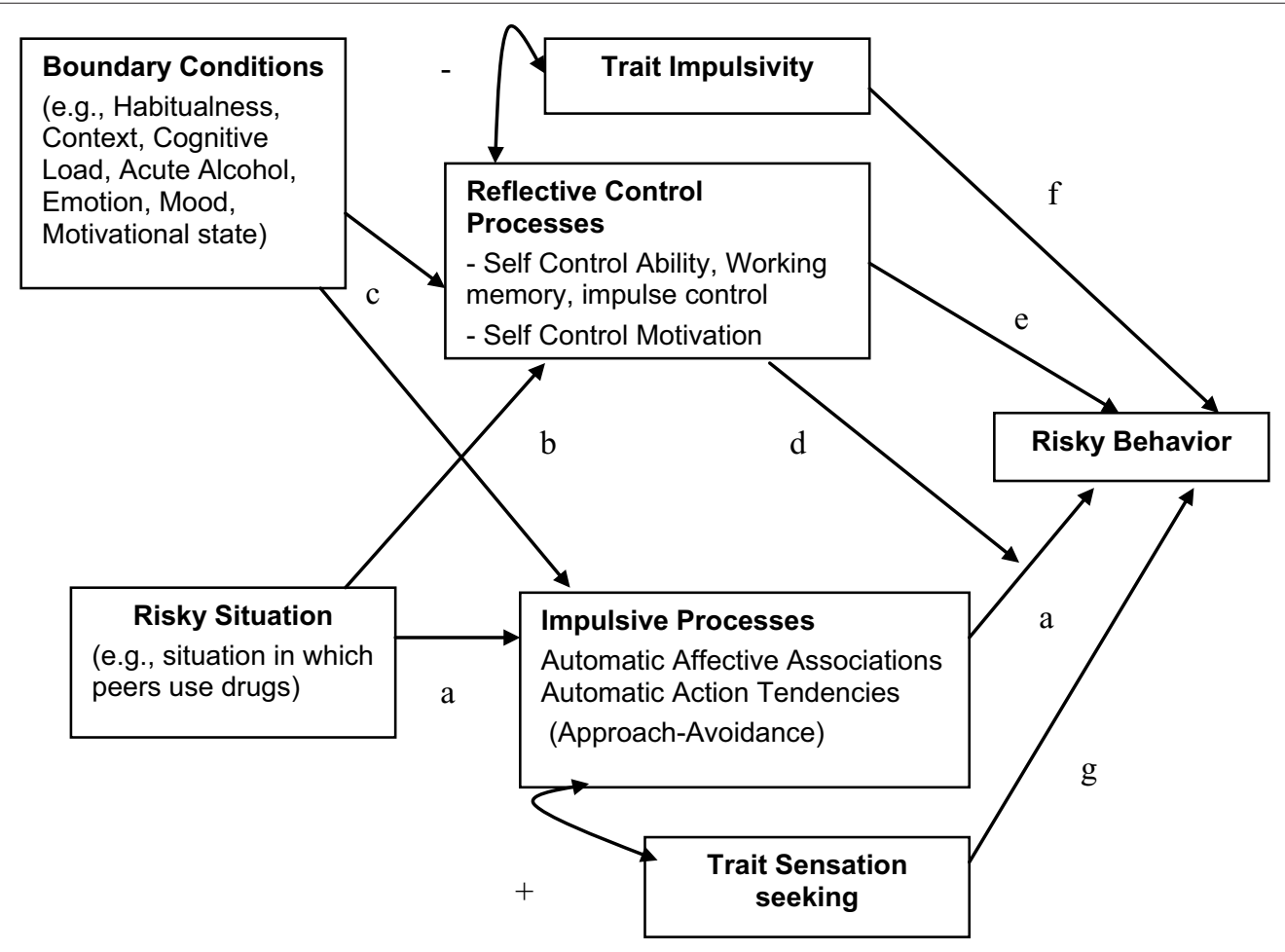

FIGURE 2 |A framework for the prediction of impulsive behavior by impulsive vs. reflective processes and associated boundary conditions (moderators). Pathway a represents the specific impulsive (associative) processes activated in the specific risky situation, which automatically activate action tendencies, usually approach. This is positively related to a general tendency to seek rewarding and stimulating experiences and sensitivity to reward (trait sensation seeking). Pathway b represents $\mathrm{EC}$ processes activated in the risky situation, including self-control ability and motivation to control. Pathway c represents the moderating effects of boundary conditions, which moderate the relative influence of pathways a and b. For example, after drinking alcohol, the impulsive (associative) processes get stronger, while the reflective processes get weaker. Pathway $d$ represents the moderation of (behavior-specific) impulsive processes by reflective processes, as demonstrated in recent studies (see also Figure 1). Pathway e represents "rational risk taking": after weighing pros and cons (reflective process), the risk is taken. Question addressed in the re-analyses presented here is whether individual differences in trait impulsivity can be viewed as a moderator, similar to executive control capacity or self-control, or whether it uniquely predicts risky behavior, independent of specific impulsive and reflective processes (pathway f). In addition, it is tested whether the moderated pathway of specific associations is robust, for controlling for trait impulsivity and sensation seeking (pathways $\mathrm{f}$ and $\mathrm{g}$ ). 
and problems, which was computed from alcohol use and problems reported 1 month after performance of the tasks (see the original publication for details). The Independent Variables were implicit and explicit alcohol-related cognitions (main effects). In addition, interaction effects of WMC (the moderator) in the prediction of alcohol use and problems by both independent variables were investigated. Implicit appetitive associations were assessed with a variety of the alcohol-arousal IAT (see above for a general explanation of the IAT). In this particular variety, participants sorted pictures of alcohol vs. non-alcoholic drinks together with words related to "excitement" (positive arousal) or "neutral". The extent to which participants were faster to sort alcoholic drinks with "excited" than in sorting non-alcoholic drinks with "excited" generates the index for alcohol-arousal associations. Explicit alcohol-arousal expectancies were assessed with a questionnaire in which participants were asked to indicate to what extent they expected each of a number of positive-arousal outcomes to happen after drinking alcohol. For this scale, the exact same words were used as in the IAT (excited, energetic, busy, lively, and wild). The moderator was WMC, assessed with the Self-Ordered Pointing Task (SOPT) (Petrides and Milner, 1982; Petrides et al., 1993; Ross et al., 2007). The main finding of this paper was that the interactions between WMC and both implicit and explicit alcohol-arousal associations were significant. Follow-up analyses indicated that in participants with relatively low WMC scores, implicit alcohol-arousal associations predicted alcohol use and problems, while in participants with relatively high scores on WMC, explicit alcohol-arousal expectancies predicted alcohol use and problems.

In the present evaluation, we conducted two supplementary analyses on this dataset. First, we investigated whether the original moderation effects would hold after controlling for self-reported impulsivity and sensation seeking. Impulsivity and sensation seeking were assessed with 18 items from the Zuckerman-Kuhlman Personality Questionnaire (Zuckerman et al., 1991), which assess impulsivity and sensation seeking (Cronbach alphas, 0.67 and 0.65, respectively in the present sample; the scales correlated at $r=0.56$ ). We repeated the original moderation analysis (Thush et al., 2008; Table 2), now including self-reported impulsivity and sensation seeking as control variables. Results in the final model (cf. step 4, Table 2, Thush et al., 2008) indicated that trait impulsivity was a significant predictor ( beta $=0.31, p=0.017$ ) but sensation seeking was not significant $(p>0.50)$. Hence, the robustness hypothesis was confirmed with regard to trait impulsivity and sensation seeking: both the interaction between implicit alcohol-arousal associations and WMC (beta $=-0.22, p=0.042$ ) and the interaction between explicit alcohol-arousal expectancies and WMC (beta $=0.33$, $p=0.003$ ) remained significant. However, impulsivity remained a significant predictor, hence, disconfirming our redundant predictors hypothesis (stating that trait impulsivity would no longer be predictive after entering moderated behavior-specific associations). Third, we investigated whether similar moderation effects would be found when WMC was replaced by an index of self-reported impulsivity. Impulsivity showed a main-effect in the prediction of alcohol use and problems ( beta $=0.26, p=0.016$ ), but the interactions with implicit and explicit alcohol-related cognitions were not significant ( $p$-values $>0.45$ ). Hence, trait impulsivity was not an alternative moderator for WMC.

\section{STUDY 2 (GRENARD ET AL., 2008)}

In this study, 145 American at-risk adolescents performed a series of computerized tasks and questionnaires in small groups, similar to Study 1 (see Grenard et al., 2008, for full description of participants and tasks). The Dependent Variables included frequency of alcohol and tobacco use, each of which was a composite score of lifetime and 1-month use assessed cross-sectionally. The Independent Variables included implicit alcohol and tobacco-related cognitions and WMC, which were the primary predictors of interest. As in Study 1, WMC, measured by the SOPT, was studied as a potential moderator of the prediction of the dependent variables. Implicit appetitive associations were assessed with three different word production association tests, including cue-behavior associations, outcome-behavior associations (verb generation), and a compound cue task that combined outcomes and situation cues. Task instructions were indirect, such that nothing about alcohol, tobacco, or other drugs was mentioned in instructions. A number of covariates or potential confounders were also assessed, such as gender, age, acculturation, and ethnicity. The central finding was that drug-related associations (for either alcohol or tobacco use) more strongly predicted the measured drug behaviors among adolescents with lower levels of WMC. This interaction effect was consistent with that uncovered in Study 1 and with the dual-process framework advanced in this article.

Here we performed two supplementary analyses on this dataset. All continuous variables in the models evaluated were centered on their means to obtain the non-standardized parameter estimates (B) reported here. Impulsivity and sensation seeking were assessed with the same instrument as used in Study 1 (Zuckerman et al., 1991). First, we replicated the original moderation analyses and findings in Grenard et al. (2008; see Table 2), while controlling for impulsivity and sensation seeking in the regression model. The overall model accounted for $41 \%$ of the variance in alcohol use. The WMC $\times$ implicit association interaction was significant, $\chi^{2}(1$, $N=145)=4.88, B=-0.07, p=0.027$, supporting the robustness hypothesis. WMC $(B=0.18, p<0.01)$ and implicit alcohol appetitive associations $(B=0.70, p<0.001)$ remained significant main effects predictors in this model. No other variables were significant in the final model. Hence, unlike Study 1, no main effect was found for trait impulsivity in addition to the specific outcome behaviorrelated processes and their interaction with WMC. Note that there was a zero-order correlation between impulsivity and alcohol use, $r=0.17,(p=0.039)$; hence as predicted the predictive power of the general trait impulsivity was taken away by introducing more specific behavior-related associations, supporting our redundant predictors hypothesis. Third, we investigated whether similar moderation effects would be found when the index of WMC was replaced by an index of self-reported impulsivity. These analyses paralleled the moderation analysis for alcohol use in Grenard et al. (2008, Table 2), using recommended robust least trimmed squares estimation methods because of the distributions of variables (Cohen et al., 2003) and replacing WMC with the self-reported impulsivity subscale. In multivariate hierarchical robust regression models, controlling for school, age, gender, ethnicity, and acculturation, impulsivity trended toward significance, $B=0.37, \chi^{2}(1$, $N=145)=3.43, p=0.064$. The set of control predictors accounted for $13 \%$ of the variance in alcohol use. When impulsivity was added 
to the model, the model accounted for $15 \%$ of the variance in alcohol use. When implicit appetitive alcohol associations were added to the model, the overall model accounted for 32\% of the variance in alcohol use, with implicit appetitive alcohol associations being the strongest predictor of alcohol use, $B=0.85, \chi^{2}$ $(1, N=145)=15.69, p<0.0001$. When we tested the interaction between trait impulsivity and implicit alcohol associations in the prediction of alcohol use, there was no significant moderator effect, $B=-0.02, \chi^{2}(1, N=145)=0.04, p=0.85$.

Hence, in Studies 1 and 2, trait impulsivity was not a moderator like WMC in the original analyses, disconfirming our alternative moderator hypothesis. However, this could be related to the fact that the method used to assess WMC was a test of function ability, while trait impulsivity was assessed with a self-report questionnaire. This issue is addressed in the final study, which used a self-report index of self-control as moderator, rather than a behavioral test of WMC.

\section{STUDY 3A AND 3B (FRIESE AND HOFMANN, 2009)}

In a third study (Study 2A in Friese and Hofmann, 2009), 156 German students were assessed with a computerized test (the single category variety of the IAT, in which no contrast category is used for alcohol, hence alcohol-positive and alcohol-negative associations are assessed), and a number of questionnaires. The Dependent Variable was the number of drinks on an average drinking occasion. Independent Variables were implicit alcohol-related associations (main effects, SC-IAT). The primary moderator in this study was a short version of self-reported self-control ability (Tangney et al., 2004). The main effect of automatic alcohol associations was significant, beta $=0.27, p=0.001$, whereas the main effect of self-control was not, $(p=0.28)$. The interaction between automatic alcohol associations and self-control was significant, beta $=-0.26$, $p=0.005$. Simple slope analyses revealed that, as expected, automatic alcohol associations were highly related to alcohol consumption for participants low in self-control, beta $=0.53, p<0.001$, but were unrelated to alcohol consumption for participants high in self-control $(p>0.50)$.

In additional analyses reported by Friese and Hofmann (2009), it was first investigated to what extent the moderation of selfcontrol was maintained after controlling for trait impulsivity. Trait impulsivity was assessed with a German adaptation of Eysenck's scale (see original publication for details). There was a strong negative correlation between self-control and impulsivity $(r=-0.58$, $p<0.001$ ), indicating that high impulsivity is related to low selfcontrol, but the overlap is far from complete (one-third of the variance), leaving room for examining a unique role for both variables. Trait impulsivity was not significantly correlated with alcohol use $(r=0.13 p=0.11)$. First, the moderation of the prediction of alcohol use by self-control was replicated after controlling for trait impulsivity $(p=0.019)$, supporting the robustness hypothesis. There was also a significant main effect of alcohol associations $(p=0.001)$, with no other significant predictors. Hence, impulsivity did not add incremental validity to the model as an independent predictor. The redundant predictor hypothesis was supported in the sense of no independent prediction, but there was also no significant correlation of impulsivity with behavior even in bivariate analyses.
When self-control was replaced by impulsivity, a marginally significant tendency was found for an interaction between alcohol associations and trait impulsivity in the expected direction (beta $=0.15, p=0.056$ ), lending partial support for the alternative moderator hypothesis. Automatic associations predicted alcohol consumption in highly impulsive individuals ( beta $=0.45$, $p<0.001)$, but not in low-impulsive individuals $(p=0.18)$.

Study 3b $(N=129$ German students; Study $2 \mathrm{~b}$ in Friese and Hofmann, 2009) involved a different measure of automatic affective associations, which does not rely on RTs, the Affect Misattribution Procedure (AMP, Payne et al., 2005). Very similar moderator effects of self-control on the relation between automatic associations toward alcohol and alcohol use ( $b e t a=-0.25$, $p=0.003)$ were obtained. Including trait impulsivity did not affect the significance of the trait self-control $\times$ automatic affective associations interaction $(p=0.037)$, supporting the robustness hypothesis. Furthermore, trait impulsivity did not yield incremental validity in this context $(p>0.27)$. Finally, substituting trait impulsivity for trait self-control yielded a marginally significant interaction effect with automatic affective associations ( $b e t a=0.15, p=0.068$ ) in the expected direction, partially supporting the alternative moderator hypothesis, and, again, no main effect of impulsivity ( $p=0.673)$.

\section{DISCUSSION OF RE-ANALYSES}

The findings of the re-analyses of the four studies can be summarized as follows. First, in all four studies, the interaction between behavior-specific impulsive processes and an index of EC remained significant after controlling for trait impulsivity, lending strong support for the robustness hypothesis. Second, trait impulsivity was found to be an independent predictor in two studies (Studies 1 and 2), and did not reach significance in Studies $3 \mathrm{a}(p=0.11)$ and $3 \mathrm{~b}(p=0.27)$. Therefore, the hypothesis that the initial predictive power of trait impulsivity would disappear after specific behaviorrelated associations and their interaction with WMC were added to the equation, could be tested in the first and second study. The outcomes of these two tests of the redundant predictors hypothesis were inconsistent: in the first study, contrary to our hypothesis, adding specific associations and their interaction with WMC to the equation, did not reduce the predictive power of trait impulsivity. In the second study, trait impulsivity did become a non-significant predictor after alcohol-related associations and the interaction with WMC was added to the regression. One possible explanation of this discrepancy is that open-ended memory associations (assessed in Study 2) related to the outcome behavior of interest do share some variance with trait impulsivity, while associations assessed in a closed RT-procedure such as the IAT (assessed in Study 1) do not. Self-report measures of impulsivity could be the result of self-perception processes, in which people recall their own previous habits while responding. Open-ended associative memory measures are designed to not only tap affective associations, but habit-related associations as well. It is possible that the two measures overlap somewhat in their ability to measure previous habits. A limitation of closed RT-measures is that the most relevant associations for an individual can be missed, because the researcher has to specify the relevant associations, whereas open-ended associative tasks allows for free competition of any potential associate (Ames et al., 2007; 
Thush et al., 2007). This could also explain the superior predictive power of these open-ended associative tasks found in a metaanalysis (Rooke et al., 2008). The third hypothesis (impulsivity as alternative moderator) was not supported in the first two studies, where it substituted a performance measure of WMC, but was partly supported in Studies 3a and 3b, where it substituted a questionnaire measure of self-control.

\section{ISSUES OF VALIDITY AND REFINING THE HYPOTHESES}

These results point to issues of test validity (Borsboom et al., 2004). Trait impulsivity is typically assessed with questionnaires, which ask for global behavioral patterns - essentially self-perceptions of previous habits. Example items (from the questionnaire used in Studies 1 and 2) are "I often do things on impulse", and "Before I begin a complicated job, I make careful plans" (a negative item). People scoring higher on this trait should relatively often act on their impulse relatively more often than individuals scoring lower, provided that the impulse is sufficiently strong. As Studies 3a and $3 \mathrm{~b}$ showed, this is negatively correlated with (self-assessed) selfcontrol. Given their general aim, these measures do not specify specific situations in which the conflict between the impulse and self-control is evident. This general issue of the validity of selfassessments may be especially problematic in relation to substance use disorders, which have been associated with reduced self-insight (Goldstein et al., 2009). Aspects of impulsivity and sensation seeking can also be assessed with behavioral performance measures such as delay discounting (although this typically involves only hypothetical gains in human versions), and the Balloon Analogue Risk Taking task, or BART (Lejuez et al., 2007). It is an interesting issue for future research to explore to what the extent to which our hypotheses are confirmed with a behavioral measure of impulsivity and/or sensation seeking.

There are also issues related to the validity of the measures of the behavior-related associations. These processes are generally assessed with implicit measures (Hofmann et al., 2008a; Stacy and Wiers, 2010), which can be conceptualized as "mini-experiments": the experimenter tries to set-up an experimental situation, which elicits the same associative processes as relevant in the real risk situation (De Houwer, 2006; Wiers et al., 2010). These measures can become more predictive when they are "primed". For example, in relation to the prediction of alcohol abuse, a prime-dose increases the predictive validity (Field et al., 2008), and in other situations, other forms of priming may increase the predictive validity of a measure of associations. For example, a movie-primed IAT predicted unique variance in bullying behavior in children, while a general (non-primed) IAT did not (van Goethem et al., 2010, see also Perugini et al., 2007, for examples of priming of associative measures). This seems a good strategy to increase the validity of implicit measures when closed RT-measures are used, but could be risky when open-ended measures of memory associations are used, because the latter tasks require indirect instructions, which do not mention the behavioral outcome of interest. It would be interesting to test our hypotheses with a primed measure of behaviorspecific associations.

Finally, regarding the validity of the EC component, this is usually assessed in a neutral format. But validity may be increased when stimuli related to the target behavior are included in the task: for example, a stop task employing not only neutral stimuli, but also stimuli related to the target behavior (e.g., alcohol-related pictures; Noel et al., 2005; Nederkoorn et al., 2009a). Further, different executive functions can have unique moderating effects (Hofmann et al., 2009). One important limitation of almost all of the research testing aspects of the dual-process models described here is that they focus entirely on individual differences in ability to control impulsive, associative processes (through measures of EC), while largely ignoring the motivation to control. However, in the studies of Friese and Hofmann (2009) a self-report measure of self-control was used, which combines (self-perceived) ability and motivation to control impulsive tendencies (see also Farris et al., 2010). Clearly, the optimal way to experimentally assess motivation and ability to control associative processes will require further studies. Finally, it should be noted that the outcome behavior is rather global here (alcohol use), and differences in findings could occur in studies of more specific consumption patterns such as binge-drinking. More generally, our argument for the importance of specific behavior-related associations to predict specific risky behaviors is related to a recurring debate in psychology about the relative merits of general vs. specific trait indicators, where the common conclusion has been that general indicators better predict general behaviors, and specific indicators specific behaviors (see Swann et al., 2007 for an excellent overview) ${ }^{1}$. New in the debate is the use of relatively novel indicators of specific behavior-related associative processes, combined with indices of ability (and sometimes motivation) to control.

Our conceptualization of impulsivity, based on dual-process models from psychology shows some conceptual similarities to "rash impulsivity" (Cyders and Smith, 2008; Cyders et al., 2009): a disposition to engage in rash action, when experiencing extreme positive or negative affect. However, there are conceptual and methodological differences. Conceptually, we argue that it is important to assess specific associative processes related to the behavior of interest, while "rash impulsivity" is conceptualized as a general trait. In our conceptualization, emotional and motivational states are important boundary conditions influencing the relative importance of associative and reflective processes. Our model would also predict stronger influence of impulsive processes in conditions of high positive or negative emotion. The difference is that the strength of behavior-specific associations is still an important predictor. Alcohol and provocation will elicit aggression in some individuals, but not in others (Wiers et al., 2009). Rash impulsivity will explain this by individual differences in negative urgency, while we found that the combination of specific associations (alcohol-power) and relatively poor EC was predictive. The second difference is methodological: rash urgency has been assessed with questionnaires, while behavior-specific associations and EC capacity are typically assessed with experimental paradigms. To the best of our knowledge, the two accounts have not directly been compared.

In conclusion, the present conceptualization of impulsivity based on general dual-process models elucidates the multifaceted nature of impulsivity and reveals much stronger levels of prediction than would be obtained using a trait approach alone. Specific risky behaviors are predicted by the combined strengths of specific

${ }^{1}$ We thank an anonymous reviewer for this suggestion. 
associative or impulsive processes related to the risky behavior and by the motivation and ability to control the risky behavior, with a number of important boundary conditions determining the relative strength of both types of processes. The present analyses partially supported the hypothesis that the predictive power of trait impulsivity disappears once behavior-specific associations, EC, and their interaction are entered into the equation. We interpreted this in relation to the validity of the measures, which should be optimized to obtain full mediation of general traits by more specific indicators of the psychological processes involved. Ultimately, these processes should be related to the underlying neurocognitive processes, if a general trait approach has any validity. Alternatively, it is possible that a general trait approach to impulsivity is not as useful as

\section{REFERENCES}

Ames, S. L., Franken, I. H. A., and Coronges, K. (2006). "Implicit cognition and drugs of abuse," in Handbook on Implicit Cognition and Addiction, eds. R. W. Wiers and A. W. Stacy (Thousand Oaks, CA: Sage), 363-378.

Ames, S. L., Grenard, J. L., Thush, C., Sussman, S., and Wiers, R. W. (2007). Comparison of indirect assessments of association as predictors of marijuana use among at-risk adolescents. Exp. Clin. Psychopharmacol. 15, 204-218.

Ames, S. L., Sussman, S., Det, C., and Stacy, A.W. (2005). Implicit cognition and dissociative experiences as predictors of adolescent substance use. Am. J. Drug Alcohol Abuse 31, 129-162.

Baumeister, R. F. (2003). Ego depletion and self-regulation failure: a resource model of self-control. Alcohol. Clin. Exp. Res. 27, 281-284.

Bechara, A. (2005) Decision making, impulse control and loss of willpower to resist drugs: a neurocognitive perspective. Nat. Neurosci., 8, 1458-63.

Borsboom, D., Mellenbergh, G. J., and van Heerden, J. (2004). The concept of validity. Psychol. Rev. 111, 1061-1071.

Chassin, L., and Barrera, M. (1993) Substance use escalation and substance use restraint among adolescent children of alcoholics. Psychol. Addict. Behav, 7, 3-20.

Cohen, J. A., Cohen, P. A., West, S. G. A., and Aiken, L. S. A. (2003). Applied Multiple Regression - Correlation Analysis for the Behavioral Sciences, 3rd Edn. Mahwah: Lawrence Erlbaum Associates.

Conrey, F. R., Sherman, J. W., Gawronski, B., Hugenberg, K., and Groom, C. J. (2005) Separating multiple processes in implicit social cognition: the quad model of implicit task performance. J. Pers. Soc. Psychol., 89, 469-87.

Conway, A. R., Kane, M. J., and Engle, R. W. (2003). Working memory capacity and its relation to general intelligence. Trends Cogn. Sci. 7, 547-552.

Cox, W. M., Fadardi, J. S., and Pothos, E. M. (2006) The addiction-Stroop Test: Theoretical Considerations and Procedural Recommandations. Psychol. Bull, 132, 443-476.

Crews, F. T., and Boettiger, C. A. (2009). Impulsivity, frontal lobes and risk for addiction. Pharmacol. Biochem. Behav. 93, 237-247.

Cyders, M. A., Flory, K., Rainer, S., and Smith, G. T. (2009) The role of personality dispositions to risky behavior in predicting first-year college drinking. Addiction, 104, 193-202.

Cyders, M. A., and Smith, G. T. (2008) Emotion-based dispositions to rash action: positive and negative urgency. Psychol. Bull., 134, 807-28.

Dahl, R. E., and Gunnar, M. R. (2009) Heightened stress responsiveness and emotional reactivity during pubertal maturation: implications for psychopathology. Dev. Psychopathol. 21, 1-6.

De Houwer, J. (2006). "What are implicit measures and why are we using them?" in Handbook of Implicit Cognition and Addiction, eds R. W. Wiers and A. W. Stacy (Thousand Oaks, CA: SAGE), 11-28.

De Houwer, J., and De Bruycker, E. (2007). The identification-EAST as a valid measure of implicit attitudes toward alcohol-related stimuli. J. Behav. Ther. Exp. Psychiatry 38, 133-143.

De Wit, H. (2009) Impulsivity as a determinant and consequence of drug use: a review of underlying processes. Addict. Biol., 14, 22-31.

Deutsch, R., and Strack, F. (2006) Reflective and impulsive determinants of addictive behaviors. Eds. R. W. Wiers and A. W. Stacy. Handbook of implicit cognition and addiction. Thousand Oaks, CA, Sage.

Evans, J. S. B. T. (2003) In two minds: Dual-process accounts of reasoning. Trends. Cogn. Sc., 7, 454-459.

Evans, J. S. B. T., and Coventry, K. (2006) A dual process approach to behav-

a focus on more specific processes explaining impulsive actions, which may provide a more conceptually viable and methodologically defensible approach.

\section{ACKNOWLEDGMENTS}

Reinout W. Wiers is supported by a grant from the Dutch National Science Foundation, N.W.O. VICI 453-08-001. Susan L. Ames and Alan W. Stacy are funded by grants from NIAAA (R21AA017996), and NIDA (DA024659; DA023368; DA024772). Wilhelm Hofmann is supported by grant HO 4175/3-1 from the German Science Foundation (DFG). The content displayed is solely the responsibility of the authors and does not necessarily represent the official views of N.W.O., NIAAA, NIDA, NIH, or DFG.

ioural addiction: The case of gambling. eds R. W. Wiers and A. W. Stacy. Handbook of Implicit Cognition and Addiction. Thousand Oaks, CA, SAGE Publishers.

Everitt, B. J., Belin, D., Economidou, D., Pelloux, Y., Dalley, J. W., and Robbins, T. W. (2008) Review. Neural mechanisms underlying the vulnerability to develop compulsive drug-seeking habits and addiction. Philos. Trans. R. Soc. Lond. B. Biol. Sci., 363, 3125-35.

Everitt, B. J., and Robbins, T. W. (2005) Neural systems of reinforcement for drug addiction: From actions to habits to compulsion. Nature Neuroscience, 8, 1481-1489.

Farris, S. R., Ostafin, B. D., and Palfai, T. P. (2010). Distractibility moderates the relation between automatic alcohol motivation and drinking behavior. Psychol. Addict. Behav. 24, 151-156.

Fazio, R. H. (1990). "Multiple processes by which attitudes guide behavior: the MODE model as an integrative framework," in Advances in Experimental Social Psychology, Vol. 23, ed. M. P. Zanna (New York: Academic Press), 75-109.

Field, M., and Cox, W. M. (2008) Attentional bias in addictive behaviors: a review of its development, causes, and consequences. Drug Alcohol Depend, 97, 1-20.

Field, M., Schoenmakers, T., and Wiers, R. W. (2008). Cognitive processes in alcohol binges: a review and research agenda. Curr. Drug Abuse Rev. 1, 263-279.

Field, M., Kiernan, A., Eastwood, B., and Child, R. (2008a) Rapid approach responses to alcohol cues in heavy drinkers. J. Behav. Ther. Exp. Psychiatry., 39, 209-18.

Field, M., Mogg, K., and Bradley, B. P. (2004) Cognitive bias and drug craving in recreational cannabis users. Drug Alcohol Depend, 74, 105-111.

Field, M., Schoenmakers, T., and Wiers, R. W. (2008b) Cognitive processes in alcohol binges: a review and research agenda. Curr. Drug Abuse Rev., 1, 263-279.

Finn, P. R., and Hall, J. (2004). Cognitive ability and risk for alcoholism: shortterm memory capacity and intelligence moderate personality risk for alcohol problems. J. Abnorm. Psychol. 113, 569-581.

Friese, M., Bargas-Avila, J., Hofmann, W., and Wiers, R. W. (2010). Here's looking at you, Bud: alcohol-related memory structures predict eye movements for social drinkers with low executive control. Soc. Psychol. Pers. Sci. 1, 143-151.

Friese, M., and Hofmann, W. (2009). Control me or I will control you: Impulse, trait self-control, and the guidance of behavior. J. Res. Pers. 43, 795-805.

Friese, M., Hofmann, W., and Wänke, M. (2008). When impulses take over: moderated predictive validity of implicit and explicit attitude measures in predicting food choice and consumption behaviour. Br. J. Soc. Psychol. 47, 397-419.

Gawronski, B., and Bodenhausen, G. V. (2006) Associative and propositional processes in evaluation: an integrative review of implicit and explicit attitude change. Psychol. Bull., 132, 692-731.

Giancola, P. R. (2000). Executive functioning: a conceptual framework for alcohol-related aggression. Exp. Clin. Psychopharmacol. 8, 576-597.

Goldstein, R. Z., Craig, A. D., Bechara, A., Garavan, H., Childress, A. R., Paulus, M. P., and Volkow, N. D. (2009). The neurocircuitry of impaired insight in drug addiction. Trends Cogn. Sci. 13, 372-380.

Greenwald, A. G., Mcghee, D. E., and Schwartz, J. L. K. (1998) Measuring individual differences in implicit cognition: The Implicit Association Test. J. Pers. Soc. Psychol., 74, 1464-1480.

Greenwald, A. G., Poehlman, T. A., Uhlmann, E., and Banaji, M. R. (2009) Understanding and using the Implicit Association Test: III Meta-analysis of 
predictive validity. J. Pers. Soc. Psychol., 97, 17-41.

Grenard, J. L., Ames, S. L., Wiers, R. W., Thush, C., Sussman, S., and Stacy, A. W. (2008) Working memory capacity moderates the predictive effects of drug-related associations on substance use. Psychol. Addict. Behav., 22, 426-432.

Grenard, J. L., Dent, C. W., and Stacy, A. W. (2009) Exposure to alcohol advertising predicts the parallel growth of alcohol associations and alcohol use. Research Society on Alcoholism (RSoA). CA: San Diego.

Gullo, M. J., and Dawe, S. (2008) Impulsivity and adolescent substance use: rashly dismissed as "allbad"? Neurosci. Biobehav. Rev., 32, 1507-18.

Hofmann, W., and Friese, M. (2008). Impulses got the better of me: alcohol moderates the influence of implicit attitudes toward food cues on eating behavior. J. Abnorm. Psychol. 117, 420-427.

Hofmann, W., Friese, M., and Roefs, A. (2009). Three ways to resist temptation: the independent contributions of executive attention, inhibitory control, and affect regulation to the impulse control of eating behavior. J. Exp. Soc. Psychol. 45, 431-435.

Hofmann, W., Friese, M., and Wiers, R. W. (2008a). Impulsive versus reflective influences on health behavior: a theoretical framework and empirical review. Health Psychol. Rev. 2, 111-137.

Hofmann, W., Gschwendner, T., Friese, M., Wiers, R. W., and Schmitt, M. (2008b). Working memory capacity and self-regulatory behavior: toward an individual differences perspective on behavior determination by automatic versus controlled processes. J. Pers. Soc. Psychol. 95, 962-977.

Hofmann, W., Rauch, W., and Gawronski, B. (2007). And deplete us not into temptation: automatic attitudes, dietary restraint, and self-regulatory resources as determinants of eating behavior. J. Exp. Soc. Psychol. 43, 497-504.

Hofmann, W., Schmeichel, B. J., Friese, M., and Baddeley,A.D. (in press). "Working memory and self-regulation," in The Handbook of Self-Regulation: Research, Theory, and Applications, Vol. 2, eds K. D. Vohs and R. F. Baumeister (New York: Guilford Press).

Hofmann, W., Gawronski, B., Gschwendner, T., LE, H., and Schmitt, M. (2005) A meta-analysis on the correlation between the implicit association test and explicit self-report measures. Pers. Soc. Psychol. Bull., 31, 1369-85.

Hofmann, W., Friese, M., and Roefs, A. (2009a) Three ways to resist tempta- tion: The independent contributions of executive attention, inhibitory control, and affect regulation to the impulse control of eating behavior. J. Exp. Soc. Psychol., 45, 431-435.

Houben, K., and Wiers, R. W. (2009). Response inhibition moderates the relationship between implicit associations and drinking behavior. Alcohol. Clin. Exp. Res. 33, 626-633.

Houben, K., and Wiers, R. W. (2006a) A Test of the Salience Asymmetry Interpretation of the Alcohol-IAT. Exp. Psychol., 53, 292-300.

Houben, K., and Wiers, R. W. (2006b) Assessing implicit alcohol associations with the Implicit Association Test: fact or artifact? Addict. Behav., $31,1346-62$

Houben, K., and Wiers, R. W. (2007a) Are drinkers implicitly positive about drinking alcohol? Personalizing the alcohol-IAT to reduce negative extrapersonal contamination. Alcohol Alcohol, 42, 301-307.

Houben, K., and Wiers, R. W. (2007b) Personalizing the alcohol-IAT with individualized stimuli: Relationship with drinking behavior and drinking-related problems Addict. Behav., 32, 2852-2864.

Houben, K., and Wiers, R. W. (2008a) Implicitly Positive about Alcohol? Implicit Positive Associations Predict Drinking Behavior. Addict. Behav., 33, 979-986.

Houben, K., and Wiers, R. W. (2008b) Measuring implicit alcohol associations via the Internet: Validation of Web-based Implicit Association Tests. Behav. Res. Method., 40, 1134-1143.

Houben, K., Nosek, B., and Wiers, R. W. (2010) Seeing the forest through the trees: A comparison of different IAT variants measuring implicit alcohol associations. Drug Alcohol Depend, 106, 204-211.

Jajodia, A., and Earleywine, M. (2003) Measuring alcohol expectancies with the implicit association test. Psychol. Addict. Behav., 17, 126-133.

Jones, B. T., and Mcmahon, J. (1998) Alcohol motivations as outcome expectancies. Eds. N. Heather, and W. R. Miller. Treating addictive behaviors New York, NY, US, Plenum Press.

Kahneman, D. (2003). A perspective on judgment and choice: mapping bounded rationality. Am. Psychol. 58, 697-720.

Kane, M. J., Bleckley, M. K., Conway, A. R. A., and Engle, R. W. (2001). A controlled-attention view of workingmemory capacity. J. Exp. Psychol. Gen. 130, 169-183.

Kelly, A. B., Masterman,P.W., and Marlatt, G. A. (2005) Alcohol related associative strength and drinking behaviours: Concurrent and prospective relationships. Drug Alcohol Rev., 24, 489-498.

Lejuez, C. W., Aklin, W., Daughters, S., Zvolensky, M., Kahler, C., and Gwadz, M. (2007). Reliability and validity of the youth version of the Balloon Analogue Risk Task (BART-Y) in the assessment of risk-taking behavior among inner-city adolescents. J. Clin. Child Adolesc. Psychol. 36, 106-111.

Maggs, J. L., and Schulenberg, J. (1998) Reasons to drink and not to drink: altering trajectories of drinking through an alcohol misuse prevention program. Appl. Dev. Sci., 2, 48-60.

Mccarthy, D. M., and Thompsen, D. M. (2006) Implicit and explicit measures of alcohol and smoking cognitions. Psychol. Addict. Behav., 20, 436-444.

McEvoy, P. M., Stritzke, W. G. K., French, D. J., Lang, A. R., and Ketterman, R. L. (2004) Comparison of three models of alcohol craving in young adults: a cross-validation. Addiction, 99, 482-497.

Miyake, A., Friedman, N. P., Emerson, M. J., Witzki, A. H., and Howerter, A. (2000). The unity and diversity of executive functions and their contributions to complex "frontal lobe" tasks: a latent variable analysis. Cogn. Psychol. 41, 49-100.

Nederkoorn, C., Baltus, M., Guerrieri, R., and Wiers, R. W. (2009a). Heavy drinking is associated with deficient response inhibition in women but not in men. Pharmacol. Biochem. Behav. 93, 331-336.

Nederkoorn, C., Guerrieri, R., Havermans, R. C., Roefs, A., and Jansen, A. (2009b). The interactive effect of hunger and impulsivity on food intake and purchase in a virtual supermarket. Int. J. Obes. (Lond.) 33, 905-912.

Nigg, J. T. (2000) On inhibition/disinhibition in developmental psychopathology: views from cognitive and personality psychology and a working inhibition taxonomy. Psychol. Bull., $126,220-46$.

Noel, X., Van der Linden, M., d'Acremont, M., Colmant, M., Hanak, C., Pelc, I., Verbanck, P., and Bechara, A. (2005). Cognitive biases toward alcohol-related words and executive deficits in polysubstance abusers with alcoholism. Addiction 100, 1302-1309.

Nordgren, L. F., Van Der Pligt, J., and Van Harreveld, F. (2008) The instability of health cognitions: Visceral states influence self-efficacy and related health beliefs. Health Psychol, 27, 722-7.

Ostafin, B., and Palfai, T. P. (2006). Compelled to consume: the Implicit Association Test and automatic alcohol motivation. Psychol. Addict. Behav. 20, 322-327.

Ouimet, A. J., Gawronski, B., and Dozois, D. J. (2009). Cognitive vulnerability to anxiety: a review and an integrative model. Clin. Psychol. Rev. 29, 459-470.

Palfai, T. P., and Ostafin, B. D. (2003). Alcohol-related motivational tendencies in hazardous drinkers: assessing implicit response tendencies using the modified-IAT. Behav. Res. Ther. 41, 1149-1162.

Payne, B. K., Cheng, C. M., Govorun, O., and Stewart, B. D. (2005). An inkblot for attitudes: affect misattribution as implicit measurement. Journal of Personality and Social Psychology, 89, 277-93.

Payne, B. K., Govorun, O., and Arbuckle, N. L. (2007). Automatic attitudes and alcohol: does implicit liking predict drinking? Cogn. Emot. 22, 238-271.

Perugini, M., O'Gorman, R., and Prestwich, A. (2007). An ontological test of the IAT: self-activation can increase predictive validity. Exp. Psychol. 54, 134-147.

Petrides, M., and Milner, B. (1982) Deficits on subject-ordered tasks after frontaland temporal-lobe lesions in man. Neuropsychologia, 20, 249-262.

Petrides, M., Alivisatos, B., Meyer, E., and Evans, A. C. (1993) Functional activation of the human frontal cortex during the performance of verbal working memory tasks. Proc. Natl. Acad. Sci. USA. 90, 878-882.

Quevedo, K. M., Benning, S. D., Gunnar, M. R., and Dahl, R. E. (2009) The onset of puberty: effects on the psychophysiology of defensive and appetitive motivation. Dev. Psychopathol., 21, 27-45.

Raine, A., Reynolds, C., Venables, P. H., and Mednick, S.A. (2002) Stimulation seeking and intelligence: a prospective longitudinal study. J. Pers. Soc. Psychol. 82, 663-674.

Robbins, T. W. (2007). Shifting and stopping: fronto-striatal substrates, neurochemical modulation and clinical implications. Philos. Trans. R. Soc. Lond., B, Biol. Sci. 362, 917-932.

Robinson, T. E., and Berridge, K. C. (2003).Addiction. Annu. Rev. Psychol. 54, 25-53.

Rooke,S.E.,Hine,D.W., and Thorsteinsson, E. B. (2008). Implicit cognition and substance use: a meta-analysis. Addict. Behav. 33, 1314-1328.

Ross, T. P., Hanouskova, E., Giarla, K., Calhoun, E., and Tucker, M. (2007). The reliability and validity of the self-ordered pointing task. Arch. Clin. Neuropsychol, 22, 449-458.

Sayette, M.A., Loewenstein, G., Griffin, K. M., and Black, J. J. (2008) Exploring the cold-to-hot empathy gap in smokers. Psychol. Sci., 19, 926-32.

Schoenmakers, T., Wiers, R. W., and Field, M. (2008) Effects of a low dose of 
alcohol on cognitive biases and craving in heavy drinkers. Psychopharmacology (Berl), 197, 169-78.

Shamosh, N.A., Deyoung, C. G., Green, A. E., Reis, D. L., Johnson, M. R., Conway, A. R., Engle, R. W., Braver, T. S., and Gray, J. R. (2008) Individual differences in delay discounting: relation to intelligence, working memory, and anterior prefrontal cortex. Psychol. Sci. 19, 904-911.

Sherman, J. W., Gawronski, B., Gonsalkorale, K., Hugenberg, K., Allen, T. J., and Groom, C. J. (2008) The self-regulation of automatic associations and behavioral impulses. Psychol. Rev., 115, 314-35.

Sher, K. J., Bartholow, B. D., Peuser, K., Erickson, D. J., and Wood, M. D. (2007) Stress-response-dampening effects of alcohol: attention as a mediator and moderator. J. Abnorm. Psychol., 116, 362-77.

Silk, J. S., Siegle, G. J., Whalen, D. J., Ostapenko, L. J., Ladouceur, C. D., and Dahl, R. E. (2009) Pubertal changes in emotional information processing: pupillary, behavioral, and subjective evidence during emotional word identification. Dev. Psychopathol., 21, 7-26.

Sloman, S. A. (1996) The empirical case for two systems of reasoning. Psychol Bull, 119, 3-22.

Smith, E. C., and Decoster, J. (2000) Dualprocess models in social and cognitive psychology: Conceptual integration and links to underlying memory systems. Person. Soc. Psychol. Rev., 4, 108-131.

Smith, E. E., and Jonides, J. (1999). Storage and executive processes in the frontal lobes. Science 283, 1657-1661.

Stacy, A. W., Ames, S. L., and Grenard, J. (2006a). "Word association tests of associative memory and implicit processes: theoretical and assessment issues," in Handbook of Implicit Cognition and Addiction, eds R. W. Wiers and A. W. Stacy (Thousand Oaks, CA: SAGE), 75-90.

Stacy, A. W., Ames, S. L., and Knowlton, B. (2004). Neurologically plausible distinctions in cognition relevant to drug abuse etiology and prevention. Subst. Use Misuse 39, 1571-1623.

Stacy, A. W., Ames, S. L., Ullman, J. B., Zogg, J. B., and Leigh, B. C. (2006b). Spontaneous cognition and HIV risk behavior. Psychol. Addict. Behav. 20, 196-206.
Stacy, A. W., and Wiers, R. W. (2010) Implicit cognition and addiction: a tool for explaining paradoxical behavior. Annu. Rev. Clin. Psychol., 6, 551-75.

Stacy, A. W. (1997) Memory activation and expectancy as prospective predictors of alcohol and marijuana use. $J$. Abnorm. Psychol., 106, 61-73.

Steinberg, L., Albert, D., Cauffman, E., Banich, M., Graham, S., and Woolard, J. (2008) Age differences in sensation seeking and impulsivity as indexed by behavior and self-report: evidence for a dual systems model. Dev. Psychol., 44, 1764-78.

Strack, F., and Deutsch, R. (2004) Reflective and impulsive determinants of social behavior. Person. Soc. Psychol. Rev., 8, 220-247.

Stritzke, W. G., and Butt, J. C. (2001) Motives for not drinking alcohol among Australian adolescents: development and initial validation of a five-factor scale. Addict. Behav., 26, 633-49.

Swann, W. B. Jr., Chang-Schneider, C., and Larsen McClarty, K. (2007). Do people's self-views matter? Self-concept and self-esteem in everyday life. Am. Psychol. 62, 84-94.

Tangney, J.P., Baumeister, R. F., and Boone, A. L. (2004). High self-control predicts good adjustment, less pathology, better grades, and interpersonal success. J. Pers. 72, 271-324.

Thush, C., and Wiers, R. W. (2007). Explicit and implicit alcohol-related cognitions and the prediction of current and future drinking in adolescents. Addict. Behav. 32, 1367-1383.

Thush, C., Wiers, R. W., Ames, S. L., Grenard, J., Sussman, S., and Stacy, A. W. (2007). Apples and oranges? Comparing indirect measures of alcohol-related cognition predicting alcohol use in at-risk adolescents. Psychol. Addict. Behav. 21, 587-591.

Thush, C., Wiers, R. W., Ames, S. L., Grenard, J. L., Sussman, S., and Stacy, A. W. (2008) Interactions between implicit and explicit cognition and working memory capacity in the prediction of alcohol use in at-risk adolescents. Drug Alcohol Depend, 94, 116-24.

Thush, C., Wiers, R. W., Moerbeek, M., Ames, S. L., Grenard, J. L., Sussman, S., and Stacy, A. W. (2009). Influence of motivational interviewing on explicit and implicit alcohol-related cognition and alcohol use in at-risk adolescents. Psychol. Addict. Behav. 23, 146-151.

van Goethem, A. A., Scholte, R. H., and Wiers, R. W. (2010). Explicit-, and implicit bullying attitudes in relation to bullying behavior. J. Abnorm. Child Psychol.

Verdejo-Garcia, A., Lawrence, A. J., and Clark, L. (2008) Impulsivity as a vulnerability marker for substance-use disorders: Review of findings from high-risk research, problem gamblers and genetic association studies. Neurosc. Biobehav. Rev., 32, 777-810.

Volkow, N. D., Fowler, J. S., and Wang, G. J. (2004) The addicted human brain viewed in the light of imaging studies: brain circuits and treatment strategies. Neuropharmacology, 47 Suppl 1, 3-13.

Weingardt, K. R., Stacy, A. W., and Leigh, B. C. (1996) Automatic activation of alcohol concepts in response to positive outcomes of alcohol use. Alcohol. Clin. Exp. Res., 20, 25-30.

Whiteside, S. P., and Lynam, D. R. (2003) Understanding the role of impulsivity and externalizing psychopathology in alcohol abuse: application of the UPPS impulsive behavior scale. Exp. Clin. Psychopharmacol, 11, 210-7.

Wiers, R. W., Van De Luitgaarden, J., Van Den Wildenberg, E., and Smulders, F. T. Y. (2005) Challenging implicit and explicit alcohol-related cognitions in young heavy drinkers. Addiction, 100, 806-819.

Wiers, R. W., Van Woerden, N., Smulders, F. T.Y., and De jong, P. J. (2002) Implicit and explicit alcohol-related cognitions in heavy and light drinkers. J. Abnorm. Psychol., 111, 648-658.

Wiers, R. W., Bartholow, B. D., van den Wildenberg, E., Thush, C., Engels, R. C. M.E., Sher, K. J., Grenard, J., Ames, S. L., and Stacy,A.W. (2007). Automatic and controlled processes and the development of addictive behaviors in adolescents: a review and a model. Pharmacol. Biochem. Behav. 86, 263-283.

Wiers, R. W., Beckers, L., Houben, K., and Hofmann, W. (2009). A short fuse after alcohol: Implicit power associations predict aggressiveness after alcohol consumption in young heavy drinkers with limited executive control. Pharmacol. Biochem. Behav. 93, 300-305.

Wiers, R. W., Beckers, L., Houben, K., and Hofmann, W. (2009a) A short fuse after alcohol: Implicit power associations predict aggressiveness after alcohol consumption in young heavy drinkers with limited executive control. Pharmacol. Biochem. Behav., 93, 300-305.

Wiers, R. W., Houben, K., Roefs, A., Hofmann, W., and Stacy, A. W. (2010). "Implicit cognition in health psychology: why common sense goes out of the window," in Handbook of Implicit Social Cognition, eds B. Gawronski and B. K. Payne (New York: Guilford), 463-488.

Wiers, R. W., and Stacy, A. W. (2010) Are Alcohol Expectancies Associations? Comment on Moss and Albery (2009) Psychological Bulletin, 136, 12-16.

Woicik, P.A., Stewart, S. H., Pihl, R. O., and Conrod, P. J. (2009). The Substance Use Risk Profile Scale: a scale measuring traits linked to reinforcementspecific substance use profiles. Addict. Behav. 34, 1042-1055.

Zack, M., Toneatto, T., and Macleod, C.M. (1999) Implicit activation of alcohol concepts by negative affective cues distinguishes between problem drinkers with high and low psychiatric distress. J. Abnorm. Psychol., 108, 518-31.

Zuckerman, M., Kuhlman, D. M., Thornquist, M., and Kiers, H. (1991). Five (or three) robust questionnaire scale factors of personality without culture. Pers. Individ. Dif. 12, 929-941.

Conflict of Interest Statement: The authors declare that the research was conducted in the absence of any commercial or financial relationships that could be construed as a potential conflict of interest.

Received: 28 April 2010; paper pending published: 19 May 2010; accepted: 06 August 2010; published online: 30 September 2010. Citation: Wiers RW, Ames SL, Hofmann W, Krank $M$ and Stacy AW (2010) Impulsivity, impulsive and reflective processes and the development of alcohol use and misuse in adolescents and young adults. Front. Psychology 1:144. doi:10.3389/ fpsyg.2010.00144

This article was submitted to Frontiers in Psychopathology, a specialty of Frontiers in Psychology.

Copyright (C) 2010 Wiers, Ames, Hofmann, Krank and Stacy. This is an open-access article subject to an exclusive license agreement between the authors and the Frontiers Research Foundation, which permits unrestricted use, distribution, and reproduction in any medium, provided the original authors and source are credited. 